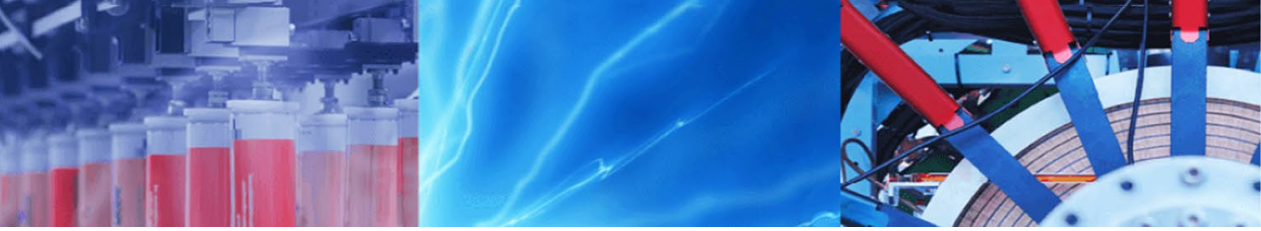

Research Article

\title{
Exploring copper as a catalyst for cost effective synthesis of polyfluorenes: an alternative to platinum and palladium
}

\author{
Deepika C. Hasija ${ }^{1}$ Jayasree Gopalakrishnan ${ }^{1,2} \cdot$ Alok V. Mishra $^{1} \cdot$ Vaijayanti D. Ghase $^{1} \cdot$ Vishwanath R. Patil $^{1}$
}

Received: 2 January 2020 / Accepted: 26 February 2020 / Published online: 6 March 2020

(c) Springer Nature Switzerland AG 2020

\begin{abstract}
In the present study, we report the synthesis of a series of anthracene based polyfluorenes containing alkyl substituted 9,10-diphenylanthracene and hydrazone substituted fluorene moieties. The polymers were synthesized via copper catalysed Ullmann coupling, which comparatively is inexpensive as compared to palladium and platinum used in Suzuki coupling. The synthesized polymers were characterized by various spectroscopic techniques. All the polymers exhibited blue emission having band gap in the range of $2.7-2.83 \mathrm{eV}$. The polymers showed good thermal stability with decomposition temperature over $330^{\circ} \mathrm{C}$ and glass transition temperature in the range of $125-140^{\circ} \mathrm{C}$. All the polymers were soluble in common organic solvents with weight average molecular weight in the range of $21,000-25,000$. The electrochemical study reveals that the HOMO energy levels of the polymers were in the range of -5.16 to $-5.26 \mathrm{eV}$ which had elevated compared with that of polyfluorene $(5.7 \mathrm{eV})$. It matched the work function of ITO and ITO/PEDOT: PSS (4.7 and $5.0 \mathrm{eV}$ respectively). These results indicated that the synthesized polymers could be promising materials for applications in light emitting diode.
\end{abstract}

Keywords Polyfluorene · Ullman coupling · Diphenylanthracene · Thermogravimetry · Electrochemical studies

\section{Introduction}

The wide application of aryl-aryl bond formation has led to enormous research in the field of biaryl synthesis with more than 700 research articles in the last 10 years. Tremendous amount of work has been devoted to palladium catalysed reactions that give conjugated polymers for example Sonogashira, Heck, Suzuki, Negishi and Stille. Transition metals like nickel and rhodium are also used for synthesis of conjugated polymers [1-16]. Though copper has been used for the synthesis of biaryls since ancient times for aryl-aryl bond formation, its use for polymerisation has not been much explored. Hence, in present work we have explored Ullmann coupling for the polymerisation of conjugated polymers. Copper being less expensive than palladium can be employed for Ullmann coupling of polymerisation which could be of a great interest $[17,18]$. This could facilitate bulk production of the light emitting polymers (LEPs) by reducing the overall cost involved with the use of expensive palladium for polymerisation. Owing to their application in solid-state lighting and flat-panel displays [19-21] LEPs have generated great interest in the field of organic light emitting diodes (OLEDs), organic solar cells, organic field effect transistors (OFETs) and biological as well as chemical sensors [22-27]. Polyfluorene (PF) is a blue light emitter which is the most extensively studied class of conjugated polymer because of its high photoluminescent (PL) efficiency, good thermal stability and

Electronic supplementary material The online version of this article (https://doi.org/10.1007/s42452-020-2344-9) contains supplementary material, which is available to authorized users.

Vishwanath R. Patil, vishwanathrpatil03@gmail.com | 'Department of Chemistry, University of Mumbai, Santacruz (E), Mumbai 400098 , India. ${ }^{2}$ Department of Chemistry, NES Ratnam College, Bhandup (W), Mumbai 4000078, India. 
charge transport property [28-30]. In the present work, we report the synthesis of PF copolymer containing diphenyl hydrazone as comonomer along with alkyl substituted 9,10 diphenyl anthracene (DPA). Hydrazone derivatives are well known charge transporting and photoconducting material. It was found that addition of hydrazone derivatives in the main PF backbone results in exciton confinement in EL devices and thus improves device efficiency. Therefore, we have used hydrazone derivative of $\mathrm{PF}$ as a comonomer to improve the charge carrier balance [31].

In addition, previous reports have revealed that the problem of poor EL and colour stability due to aggregation associated with PF. These problems can be overcome by introducing bulky $\pi$ conjugated dopants $[32,33]$ which facilitate energy transfer between the two units. DPA due to its high fluorescence quantum yield and good electrochemical properties have found numerous applications in optoelectronic devices [34-38]. Therefore, anthracene derivatives has attracted great interest as blue lightemitting materials $[39,40]$. Hence, a series of structurally modified non-symmetric 9,10-diphenylanthracene derivatives were synthesized and investigated. To enhance film forming properties of the DPA derivatives they were nonsymmetrically substituted at the 2 nd position by different length alkyl groups. Although PF show high PL and EL efficiency, good solubility and thermal stability they usually exhibit high hole injection barrier due to deep HOMO levels of about $-5.7 \mathrm{eV}$ which does not match well with the work function of ITO and ITO/PEDOT (about 4.7 and $5.0 \mathrm{eV}$ respectively). Combining fluorene with anthracene having a low band gap can significantly lower the hole injection barrier and fine tune combination zone in the emission layer [41]. To our knowledge there are no reports showing encorporation of various alkyl substituted DPA moiety through its 9-10 positions in the PF containing diphenyl hydrazone. Hence our approach was to synthesize deep blue emitting copolymers containing these two monomers in the same polymer chain.

\section{Experimental}

\subsection{Materials}

All chemicals and reagents were purchased from Sigma Aldrich and SD fine and were used without any further purification. All the reactions of moisture sensitive compounds were carried out in a dry reaction vessel under nitrogen atmosphere. All of the solvents were used after purification according to conventional methods reported in the literature. Spectroscopic-grade THF (Aldrich Chemical) was used for all absorption and emission experiments.
2,7-Dibromofluorenone was synthesized according to procedures outlined in the literature [42].

\subsection{Characterization}

Bruker AMX-300 spectrometer was used to record the ${ }^{1} \mathrm{H}$ and ${ }^{13} \mathrm{C}$ NMR spectra in $\mathrm{CDCl}_{3}$ and chemical shift reported in $\delta$ ppm values relative to TMS (tetramethyl silane) as an internal standard. FTIR spectra were recorded on a Perkin-Elemer 1600 series spectrophotometer in $\mathrm{KBr}$ discs. Mass spectra were recorded using shimadzu GCMS/QP 2010 spectrophotometer. UV-Vis spectra were recorded by shimadzu UV-2100 spectrophotometer. Photoluminescence spectra were recorded on Perkin-Elmer Instruments LS55 Luminescence Spectrometer of wavelength range $200-800 \mathrm{~nm}$. Thermogravimetric measurements of the polymers were performed on Perkin-Elmer/Pyris Diamond thermo analyser at heating rate of $10^{\circ} \mathrm{C}$ per minute in the controlled nitrogen atmosphere. X-ray diffraction experiments were carried out using shimadzu XRD-7000 $X$-ray diffractrometer. The XRD pattern was obtained using $\mathrm{Cu}(\mathrm{Ka})(\lambda=1.542 \AA$ ) $)$. The molecular weight of the polymers were analysed by gel permeation chromatography (GPC). The measurement was done on a Perkin Elmer series 200 GPC equipped with an isocratic pump, a solvent degasser, a column oven, a refractive index (RI) detector, and Chromatographic Column PL gel 10 m Mixed-B, $300 \mu 7.5 \mathrm{~mm}$ at a flow rate of $1 \mathrm{~mL} / \mathrm{min}$ using THF as the eluent and polystyrene standards for calibration. Cyclic voltammetry (CV) experiments were performed using an Autolab ADC 164 electrochemical analyser operated at a scanning rate of $50 \mathrm{mV}$, the supporting electrolyte was $0.1 \mathrm{M}$ tetrabutylammonium hexafluorophosphate which was dissolved in $\mathrm{CH}_{2} \mathrm{Cl}_{2} \cdot 0.1 \mathrm{M}$ of the sample and $0.1 \mathrm{M}$ of $\mathrm{Bu}_{4} \mathrm{NPF}_{6}$ with a glassy carbon working electrode, a Pt counter electrode, a $\mathrm{Ag} / \mathrm{AgCl}\left(\mathrm{Ag} / \mathrm{Ag}^{+}\right)$reference electrode and a ferrocene/ferrocenium $\left(\mathrm{Fc} / \mathrm{Fc}^{+}\right)$internal reference. Melting points were determined by model Thermo cal, Analab scientific instrument Pvt Ltd. Crystalline behaviours of the compound were studied by XRD.

\subsection{Synthesis of the monomers and polymers}

\subsubsection{Synthesis of [Aza(2,7-dibromofluoren-9-ylidene) methyl]diphenylamine (FDPA) [M1]}

Into a three necked round bottom flask a mixt ure of 2,7-dibromo-9-fluorenone (1 g, $3 \mathrm{mmol}), 1$,1-diphenylhydrazine hydrochloride $(0.75 \mathrm{~g}, 3.39 \mathrm{mmol})$ and $50 \mathrm{~mL}$ of ethanol were added. The mixture was heated at $60-70{ }^{\circ} \mathrm{C}$ for $24 \mathrm{~h}$. The resultant product was an orange precipitate. After cooling, the orange precipitate obtained was washed with hot methanol, and then dried under vacuum. 
The resulting solid was further purified through silica gel chromatography eluted by PET ether to afford $1.04 \mathrm{~g}$ of an orange solid (yield 79.8\%), [31]. The orange coloured solid product was formed. Reaction is as shown in Scheme 1.

NMR signals of FDPA: yield 75\%; M.P: $230{ }^{\circ} \mathrm{C} .{ }^{1} \mathrm{H}$ NMR (300 MHz, $\left.\mathrm{CDCl}_{3}, \delta \mathrm{ppm}\right): 8.11(s, 1 \mathrm{H}), 7.46(t, 2 \mathrm{H}), 7.41(d$, $1 \mathrm{H}), 7.36(d, 1 \mathrm{H}), 7.32(t, 4 \mathrm{H}), 7.24(d, 2 \mathrm{H}), 6.89(s, 1 \mathrm{H}) ;{ }^{13} \mathrm{C}$ NMR: (75 MHz, $\mathrm{CDCl}_{3}, \delta$ in ppm): $120.72,121.229,122.01$, $122.44,125.09,125.24,129.38,129.94,130.37,131.87$, $132.38,137.06,139.27,140.71,147.34,148.51$. Anal. Calcd for $\mathrm{C}_{25} \mathrm{H}_{16} \mathrm{Br}_{2} \mathrm{~N}_{2} \mathrm{C}, 59.55 ; \mathrm{H}, 3.2 ; \mathrm{Br}, 31.69 ; \mathrm{N}, 5.56$. \%; Found: $C, 59.53 ; \mathrm{H}, 3.16 ; \mathrm{Br}, 32.01 ; \mathrm{N}, 5.52 \%$.

\subsubsection{Synthesis of acene monomer}

The monomers were synthesized according to methods reported in the literature. Synthesis of acene monomers comprises of two steps as shown in Scheme 2. General scheme for the synthesis is outlined in Scheme S1.

2.3.2.1 Synthesis of 2-alkyl-9,10-di (p-methoxyphenyl) anthracene Various alkyl substituted 9, 10 DPA were synthesized according to reported methods [43-51].

\subsection{General polymerization}

The monomer $\mathbf{M} \mathbf{1}$ was polymerised with monomer M2, M3, M4 to give desired polyfluorene. The general method for polymerisation is illustrated in Scheme 3. The copolymers were synthesized through copper iodide catalysed Ullman coupling. For the synthesis of polymer in an oven dried round bottom flask copper (I) iodide ( $20 \mathrm{mg}$, $0.10 \mathrm{mmol}, 10 \mathrm{~mol} \%)$, picolinic acid $(24 \mathrm{mg}, 0.20 \mathrm{mmol}$, $20 \mathrm{~mol} \%)$, FDPA (M1) $(0.504 \mathrm{~g}, 1.0 \mathrm{mmol})$, M2, M3, M4 $(1.0 \mathrm{mmol})$, and $\mathrm{K}_{3} \mathrm{PO}_{4}(0.424 \mathrm{~g}, 2.0 \mathrm{mmol})$ were dissolved in DMSO $(2.0 \mathrm{~mL})$. The flask was placed in a preheated oil bath at $80^{\circ} \mathrm{C}$ and the reaction mixture was stirred vigorously for $24 \mathrm{~h}$. After the polymerization was completed, bromobenzene was added for end capping of hydroxyl groups. The reaction mixture was cooled to room temperature. Ethyl acetate $(10 \mathrm{~mL})$ and $\mathrm{H}_{2} \mathrm{O}(1 \mathrm{~mL})$ were added and the mixture was stirred. The organic layer was separated and the aqueous layer was extracted twice more with ethyl acetate $(10 \mathrm{~mL})$. The combined organic layer was dried over $\mathrm{Na}_{2} \mathrm{SO}_{4}$ and filtered through a pad of silica gel. The filtrate was concentrated and the resulting residue was precipitated in methanol. Pale orange coloured PFs with a yield of $70-75 \%$ were obtained.

Using the similar reaction scheme series of FDPA-diphenylacene polymers PF 1, PF 2, PF $\mathbf{3}$ were synthesized.

Poly (FDPA-MDPA) (PF 1) ${ }^{1} \mathrm{H}$ NMR $\left(300 \mathrm{MHz}, \mathrm{CDCl}_{3}, \delta\right.$ ppm): $1.26\left(\mathrm{~s}, 3 \mathrm{H},-\mathrm{CH}_{3}\right), 6.92-7.48(\mathrm{~m}, 74 \mathrm{H}, \mathrm{Ar}-\mathrm{H}){ }^{13} \mathrm{C}$ NMR (75 MHz, $\mathrm{CDCl}_{3}, \delta \mathrm{ppm}$ ): 31.75 (carbon of $-\mathrm{CH}_{3}$ ), 120.91-148.75 (aromatic carbon).

Poly (FDPA-EDPA) (PF 2) ${ }^{1} \mathrm{H}$ NMR $\left(300 \mathrm{MHz}, \mathrm{CDCl}_{3}, \delta\right.$ ppm): $1.24\left(t, 3 \mathrm{H},-\mathrm{CH}_{3}\right), 2.72\left(q, 2 \mathrm{H},-\mathrm{CH}_{2}\right), 6.95-7.73$ $(m, \mathrm{Ar}-\mathrm{H}) ;{ }^{13} \mathrm{C} \mathrm{NMR}\left(75 \mathrm{MHz}, \mathrm{CDCl}_{3}, \delta \mathrm{ppm}\right): 15.48$ (carbon of $\left.-\mathrm{CH}_{3}\right), 29.46$ (carbon of $-\mathrm{CH}_{2}$ ), 115.51-155.26 (aromatic carbon).

Poly (FDPA-TDPA) (PF 3) ${ }^{1} \mathrm{H}$ NMR $\left(300 \mathrm{MHz}, \mathrm{CDCl}_{3}, \delta\right.$ ppm): $1.3\left(\mathrm{~s}, 9 \mathrm{H},-\mathrm{CH}_{3}\right), 6.94-7.77(m, 74 \mathrm{H}, \mathrm{Ar}-\mathrm{H}) ;{ }^{13} \mathrm{C}$ NMR: (75 MHz, $\mathrm{CDCl}_{3}, \delta \mathrm{ppm}$ ): 30.99 (carbon of $-\mathrm{CH}_{3}$ ), 35.12 (carbon of tert C), 115.5-155.19 (aromatic carbon).

\section{Result and discussion}

\subsection{Structural characterization}

The structural characterization of the monomers was done by ${ }^{1} \mathrm{H},{ }^{13} \mathrm{C}$ NMR, and FTIR spectroscopy. Polymerisation was confirmed from FTIR (Fig. S7) by the absence of absorption peaks in the region $3400 \mathrm{~cm}^{-1}$ indicating completion of polymerization and termination of the hydroxy group of alkyl substituted DPA monomers. The strong absorption peak in the range $1200-1300 \mathrm{~cm}^{-1}$ was observed due to

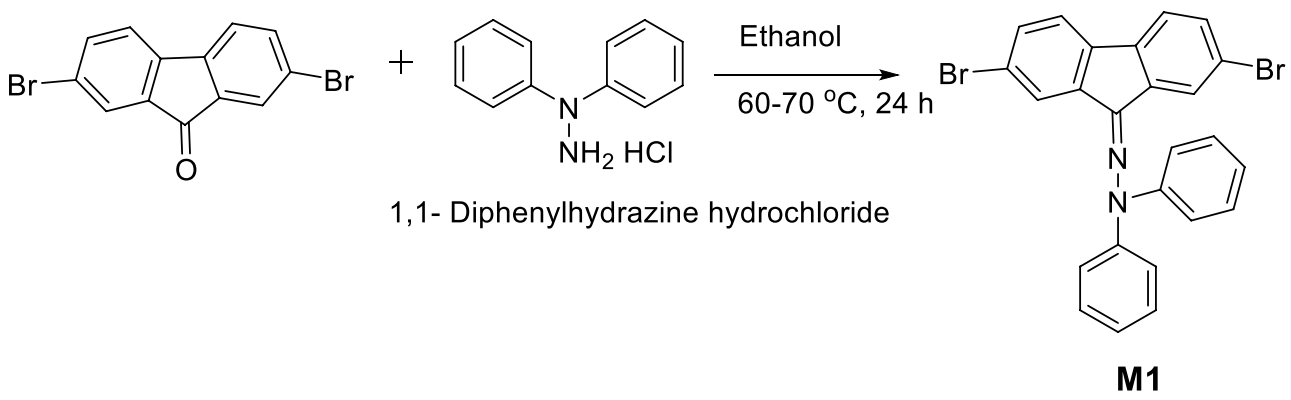

Aza(2,7-dibromofluoren-9-ylidene)methyl] diphenylamine (FDPA)

Scheme 1 Synthesis of [Aza(2,7-dibromofluoren-9-ylidene)methyl] diphenylamine (FDPA) 
<smiles>[R]C1=CC2C(=O)c3ccccc3C(=O)C2C=C1</smiles><smiles>[R]c1ccc2c(-c3ccc(O)cc3)c3ccccc3c(-c3ccc(OCC(=O)N[O+])cc3)c2c1</smiles>

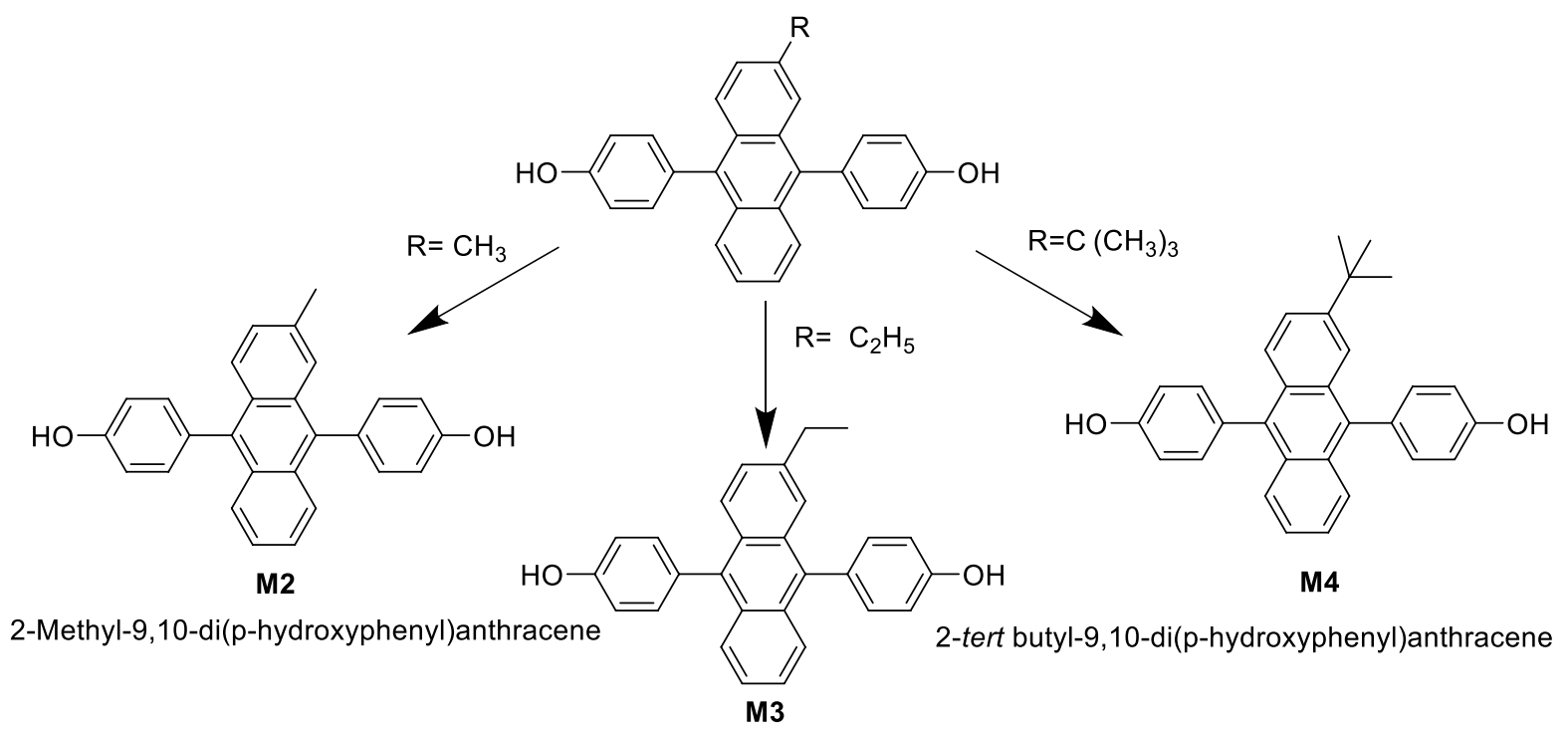

2-Ethyl-9,10-di(p-hydroxyphenyl)anthracene

Scheme 2 Synthesis of 2-methyl-9,10-di (p-hydroxyphenyl) anthracene

$\mathrm{C}-\mathrm{O}-\mathrm{C}$ stretching vibrations of ether linkage on the main polymer backbone. Formation of polymers via removal of $\mathrm{HBr}$ molecule was confirmed by this observation. The sharp band in the range $1490-1500 \mathrm{~cm}^{-1}$ was observed in the infrared spectra due the frequency of $C=C$ vibration of conjugated aromatic rings.

\subsection{Optical properties}

Normalised UV-vis absorption and photoluminescence spectra of all polymers in solution and in solid films is represented in Fig. 1. The solution-phase UV-Vis absorption and fluorescence emission spectra were recorded at room temperature in dilute THF solution. A homogeneous and pinhole-free thin film was obtained via spin casting from a $\mathrm{CHCl}_{3}$ solution. To avoid the possibility of concentration quenching or reabsorption and reemission, the solvent was purged with $\mathrm{N}_{2}$ prior to measurement. All spectroscopic data for measurements in solution and thin film are summarized in Table 1.

The absorption spectra of films and corresponding solutions were almost identical. According to literature typical 


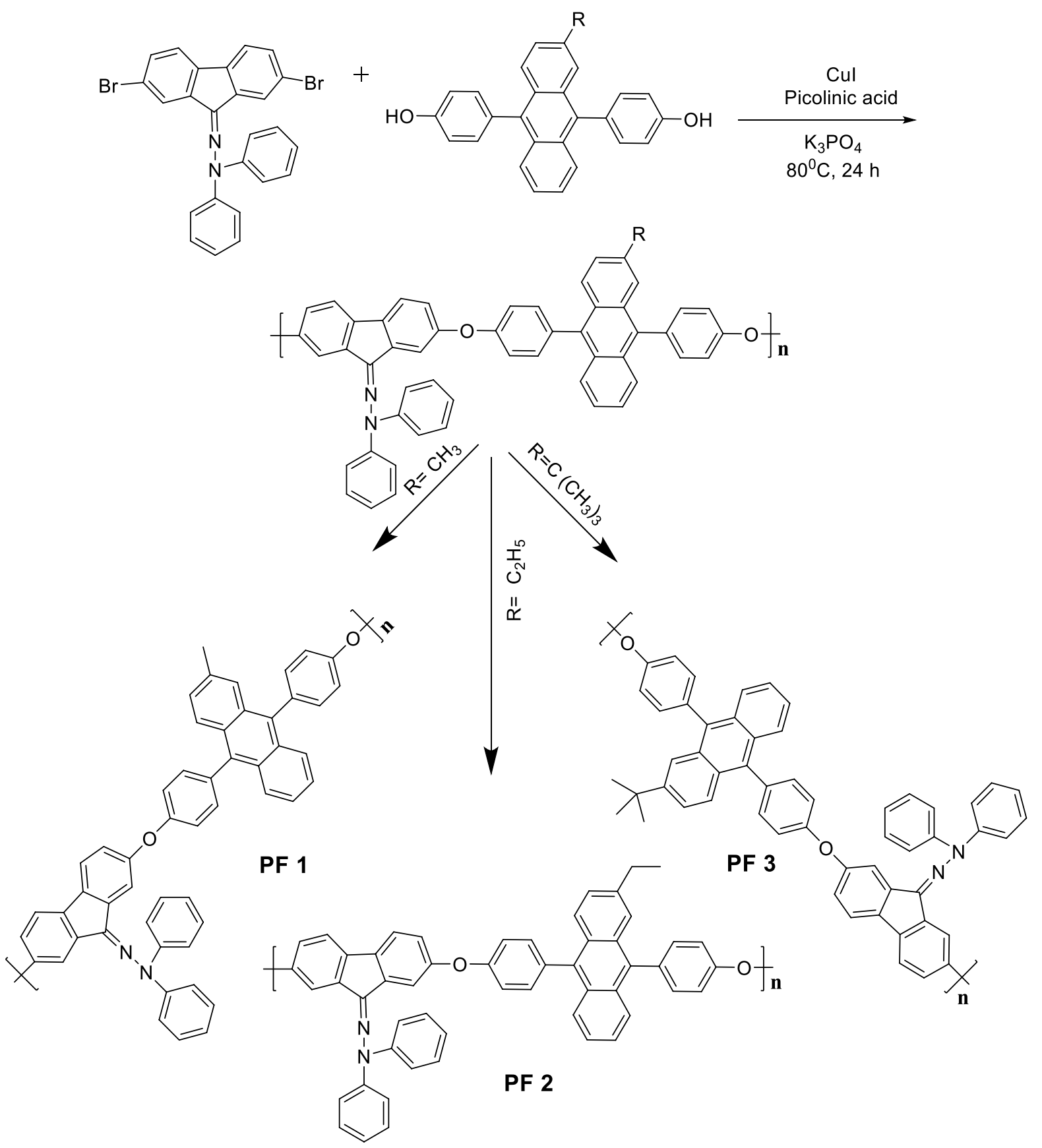

Scheme 3 Synthesis of polymer

absorption maxima of the anthracene occurs at 359,377 , $396 \mathrm{~nm}$ and the absorption for fluorene occurs at $390 \mathrm{~nm}$ [52]. The absorption maxima of synthesized polymers were blue shifted to $320 \mathrm{~nm}$. The increase in absorption by the anthracene group results in the observed blue shift. The absorption by anthracene group results in shoulders observed at 298 and $360 \mathrm{~nm}$ and was independent of the substituents [53]. With increase of length of side chain on anthracene the absorption maxima was blue shifted due to increase in effective conjugation length. The polymer thin film showed broadening of the absorption band and upward shift of the shoulder peak as compared to that of solution due to some aggregation of polymers in the solid state [54]. The optical band gap of the PFs were calculated from absorption edge and were found in the range of 2.7, 2.83 and $2.83 \mathrm{eV}$ respectively. A wide band gap of polymer is desirable for their use as charge-injection materials for blue-light emitting materials. These results indicated that 


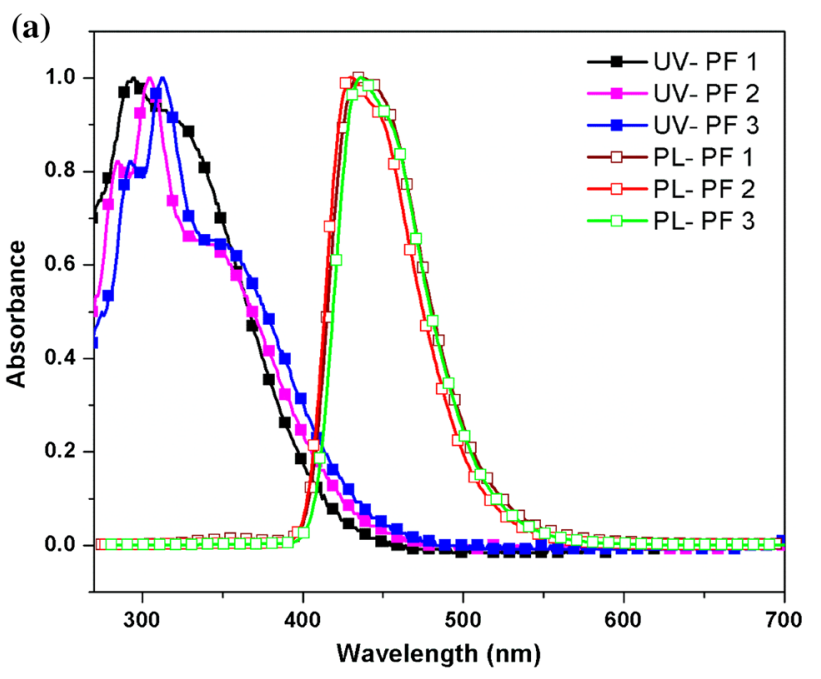

(b)

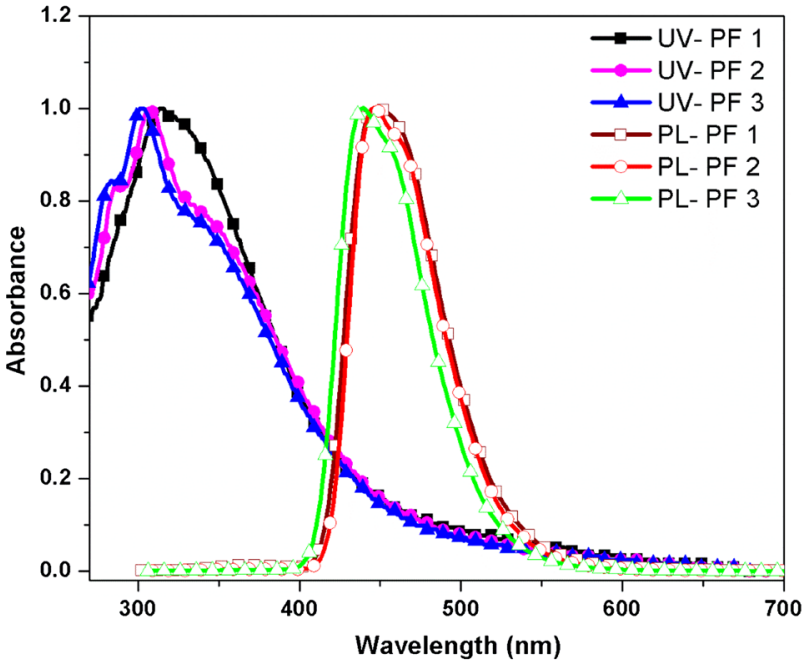

Fig. 1 Normalised UV-Vis and PL spectra of polymers a in solution b solid film

the alkyl side chains used in the polymers have little effect on the band gap of the polymers.

Upon UV excitation, solutions of the polymers exhibited very intense fluorescence with a maximum at $442 \mathrm{~nm}$ for PF 1, $434 \mathrm{~nm}$ for PF 2 and $427 \mathrm{~nm}$ for PF 3, respectively. The solid PL showed a 10-15-nm red shifted emission in comparison with those of a solution this can be attributed to the aggregation of polymer chains in solid. Moreover, the solid PL spectrum of polymer was identical of solution one. This may be due to the distorted conjugate backbone of anthracene and the DPA substituted fluorene which inhibited the intermolecular interaction between them. The emission band was much narrower than the absorption bands and showed well-resolved vibronic bands was consistent with the emission from localized excited states which may be due to migration of the excitons along the polymer main chain to segments of low energy states. The emission spectrum of PFs suggested that they showed emission in the blue region and can be used as blue emitters for optoelectronic applications. The fluorescence quantum yield of the polymers was calculated using 9,10-diphenylanthracene as a standard were found in the range of $47-69 \%$ in solution and $14-21 \%$ in thin film.

\subsection{Electrochemical properties}

Electrochemical properties of the polymer are shown in Fig. 2. All copolymer samples were analysed using ferrocene as an internal standard and monitored in a standard three electrode electrochemical cell. The samples were dissolved in dichloromethane. 0.1 M n-Bu${ }_{4} \mathrm{NBF}_{4}$ dissolved in $\mathrm{CH}_{2} \mathrm{Cl}_{2}$ was used as the electrolyte solution and the scanning rate was $100 \mathrm{mV} / \mathrm{s}$. The cyclic voltammogram was calibrated by ferrocene-ferrocenium redox couple which is assumed to have an absolute energy level of $4.8 \mathrm{eV}$ below the vacuum level. Cyclic voltammograms of polymers showed similar behaviour as polyfluorene, having a comparatively broad quasireversible wave. The results indicate that with the introduction of anthracene unit the HOMO and LUMO levels of the polymers had slightly increased. The onset of oxidation $\left(E_{\text {ox }}\right)$ peak potentials for PF 1, PF 2 and PF 3 were measured to be $0.86,0.76$ and $0.82 \mathrm{eV}$ respectively. Regardless of the substituents, the polymers showed similar onsets. Accordingly, the corresponding HOMO and LUMO energy levels of PF 1, PF $\mathbf{2}$ and PF $\mathbf{3}$ were determined according to the empirical formula. HOMO energy levels of the polymer were estimated to be $-5.26,-5.16$ and $-5.22 \mathrm{eV}$, respectively. The LUMO levels of the polymers were obtained from the HOMO levels and corresponding optical bandgaps. Thus, the calculated LUMO levels for the polymers were -2.56 ,
Table 1 Optical properties of polymers

\begin{tabular}{|c|c|c|c|c|c|c|}
\hline \multirow[t]{2}{*}{ Polymer } & \multicolumn{2}{|c|}{ UV absorption $\left(\lambda_{\max }(\mathrm{nm})\right)$} & \multicolumn{2}{|c|}{$\mathrm{PL}\left(\lambda_{\max }(\mathrm{nm})\right)$} & \multicolumn{2}{|c|}{$\phi(\%)^{a}$} \\
\hline & THF & Film & THF & Film & THF & Film \\
\hline PF 1 & 302 & 322 & 442 & 455 & 47 & 14 \\
\hline PF 2 & 307 & 309 & 434 & 449 & 52 & 16 \\
\hline PF 3 & 313 & 300 & 427 & 438 & 69 & 21 \\
\hline
\end{tabular}

a Measured using 9, 10-DPA as standard 


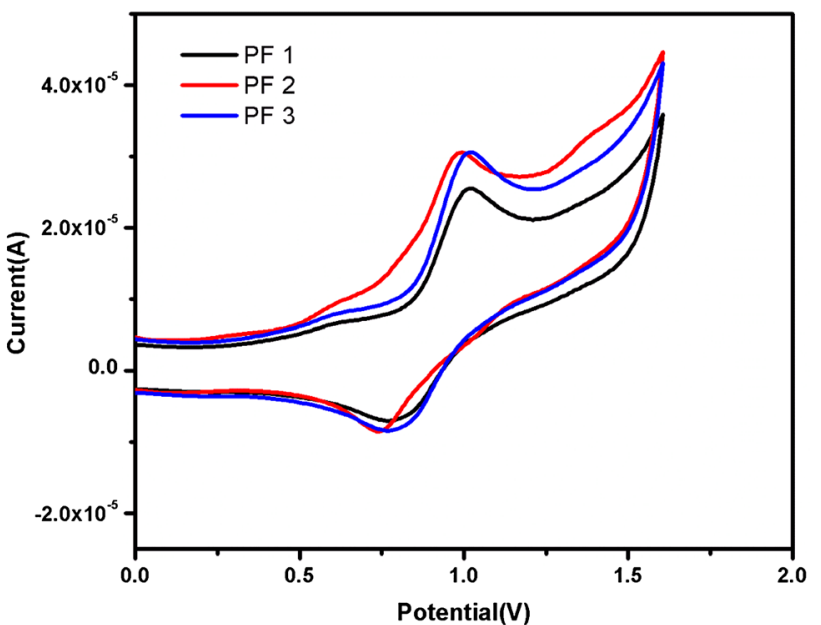

Fig. 2 Cyclic voltammograms of polymers

Table 2 Electrochemical properties of polymers

\begin{tabular}{lllll}
\hline Polymer & $E_{\mathrm{g}}^{\mathrm{a}}(\mathrm{eV})$ & $E_{\mathrm{ox}}^{\mathrm{b}}(\mathrm{eV})$ & $E_{\text {HOMO }}^{\mathrm{c}}(\mathrm{eV})$ & $E_{\text {LUMO }}^{\mathrm{d}}(\mathrm{eV})$ \\
\hline PF 1 & 2.7 & 0.86 & -5.26 & -2.56 \\
PF 2 & 2.83 & 0.76 & -5.16 & -2.33 \\
PF 3 & 2.83 & 0.82 & -5.22 & -2.39 \\
\hline
\end{tabular}

${ }^{\mathrm{a}}$ The edge of UV spectrum in thin film state

${ }^{b}$ Onset oxidation potential

'The equation $E_{\mathrm{HOMO}}=-\left(E_{\mathrm{ox}}+4.4\right)$

${ }^{\mathrm{d}}$ The equation $E_{\mathrm{LUMO}}=E_{\mathrm{HOMO}}-E_{g}^{\mathrm{opt}}$

-2.33 , and $-2.39 \mathrm{eV}$ respectively which was almost similar to other reported polymers [55]. Table 2 compares the electrochemical properties of all copolymers.

\subsection{Thermal studies}

The thermal properties of the synthesized polymers were studied by TGA and DSC under nitrogen atmosphere as shown in Fig. 3 and Table 3. The polymers exhibited good thermal stability with onset degradation temperature above $330{ }^{\circ} \mathrm{C}$ and $10 \%$ weight loss occurring at $410^{\circ} \mathrm{C}$. All the polymers showed two step decomposition processes with decomposition temperature in the range of $330-750^{\circ} \mathrm{C}$. The polymers exhibited degradation in two step one at a lower temperature in the range of $330-490^{\circ} \mathrm{C}$ corresponding to the degradation of alkyl group and at $500-750{ }^{\circ} \mathrm{C}$ for main chain degradation. The decomposition onset temperature for $\mathbf{P F} \mathbf{3}$ was $5^{\circ} \mathrm{C}$ higher than that of PF 1 and PF 2 indicating that as the alkyl branching was increased thermal stability of the polymer was slightly improved. Polymers did not show significant weight loss below $100^{\circ} \mathrm{C}$ that indicated absences of moisture in the polymer chain.

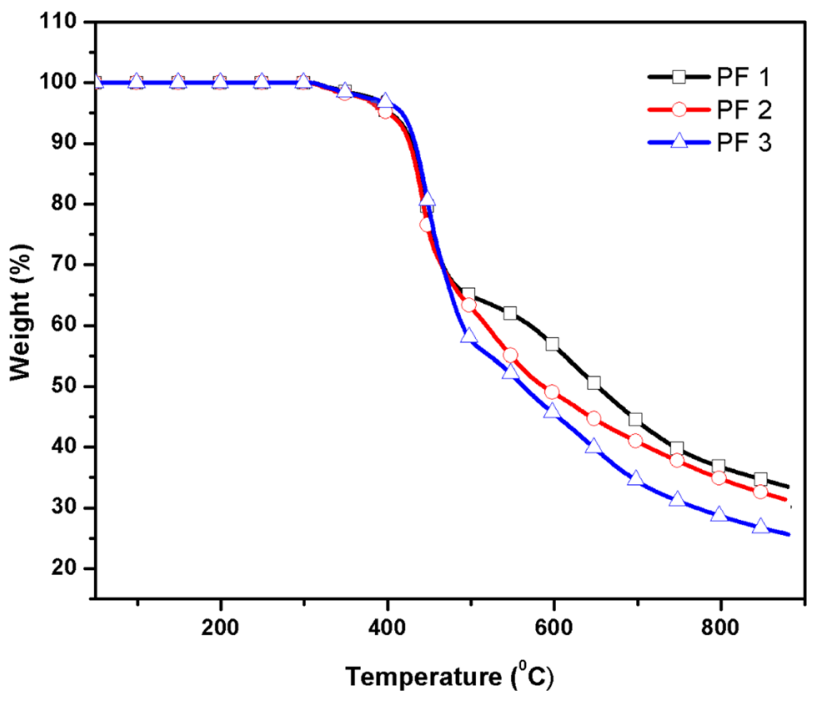

Fig. 3 Thermograms of polymers

Table 3 Molecular weights and thermal analysis data of polymers

\begin{tabular}{llllll}
\hline Polymer & $M_{n}^{a}$ & $M_{w}^{a}$ & $\mathrm{PDI}\left(M_{w} / M_{n}\right)$ & $T_{d}^{\mathrm{b}}\left({ }^{\circ} \mathrm{C}\right)$ & $T_{g}^{\mathrm{c}}\left({ }^{\circ} \mathrm{C}\right)$ \\
\hline PF 1 & 11700 & 25200 & 2.15 & 335 & 120 \\
PF 2 & 10900 & 21100 & 1.93 & 338 & 125 \\
PF 3 & 13800 & 24700 & 1.78 & 341 & 130 \\
\hline
\end{tabular}

a Determined by GPC in THF (Polystyrene used as standard)

${ }^{\mathrm{b}} 10 \%$ weight loss temperature by TGA under $\mathrm{N}_{2}$

${ }^{\mathrm{C}} \mathrm{Glass}$ transition temperature determined by DSC

DSC analysis was also performed to establish thermally induced phase transition behaviour of the copolymers. The results are included in Table 3 and the thermogram is shown in Fig. 3. In all cases, one thermal transition above $100{ }^{\circ} \mathrm{C}$ was detected which corresponds to glass transition temperature and no other crystallization and melting peaks were found. All the polymers exhibited high glass transition temperature $\left(T_{\mathrm{g}}\right)$ ranging from 120 to $130{ }^{\circ} \mathrm{C}$. According to literature $T_{\mathrm{g}}$ of Polyfluorene was reported as $51^{\circ} \mathrm{C}$ [56]. The significant increase in the $T_{\mathrm{g}}$ can be attributed to the incorporation of DPA in the polymer backbone which resulted in formation of three dimensional crosslinked polymeric network increasing the chain rigidity. Therefore incorporation of alkyl substituted DPA into the polymeric backbone results into increases in thermal stability and leads to have higher $T_{\mathrm{g}}$ which is vital for polymer functioning as active layers in LED applications.

Thus, it was suggested that, introduction of alkyl substituted DPA along with diamine substituted fluorene in the polymeric backbone forming three dimensional crosslinked polymeric network leads to high thermal stability of the polymers preventing deformation and aggregation of 
the emitting layer due to the heat produced during device fabrication and its operation.

\subsection{X-ray diffraction studies}

Polymer crystallinity is one of the important properties of all polymers since polymer exists both in crystalline and amorphous form. Crystallite size of the polymer is used to describe the nature of polymer and extent of crystallinity present in the polymer sample. The XRD patterns of polymers are shown in the Figure S8. The crystallite sizes of the polymers were calculated using Deby-Scherrer relation and are as shown in Table S1. The X-ray diffractogram of polymers showed small, well resolved peaks with varying intensity. Also no noticeable broadening area under the peaks was observed in all the diffractograms. This suggested that, the synthesized polymers were more crystalline in nature.

\section{Conclusion}

In conclusion, we successfully synthesized fluorene based copolymers containing anthracene via copper catalysed Ullmann coupling. The polymers were obtained in good yields. The polymers synthesized had fairly high molecular weight. Thus copper could be an alternative for the catalysis of polymerisation. Encorporation of anthracene units in the polymer chain provided rigidity and three dimensional arrangements to the structure thus increasing its thermal stability. Also aggregation which is a most commonly encountered problem with polyfluorenes was significantly reduced due to the steric hindrance and rigid arrangement achieved by introducing hydrazone moiety on fluorene, this results in almost identical PL emission in both solid as well as solution state. The polymers emitted light in the blue region and the PL spectra was free of any green emission a problem encountered with PF. All blue light emitting polymers thus synthesized were thermally stable, highly fluorescent with wide semiconducting bandgaps and were having a morphology suitable for fabricating OLED.

\section{Compliance with ethical standards}

Conflict of interest The authors declare no conflict of interest.

\section{References}

1. Donat-Bouillud A, Levesque I, Tao Y, D'lorio M, Beaupre S, Blondin P, Ranger M, Bouchard J, Leclerc M (2000) Light-emitting diodes from fluorene-based $\pi$-conjugated polymers. Chem Mater 12:1931-1936
2. Wang S, Oldham WJ, Hudack RA, Bazan GJ (2000) Synthesis, morphology, and optical properties of tetrahedral oligo(phenylenevinylene) materials. J Am Chem Soc 122:5695-5709

3. Zotti G, Schiavon G, Zecchin S, Morin JF, Leclerc M (2002) Electrochemical, conductive, and magnetic properties of 2,7-carbazole-based conjugated polymers. Macromolecules 35:2122-2135

4. Moore JS, Zhang JS (1993) Efficient synthesis of nanoscale macrocyclic hydrocarbons. Angew Chem 31:922-924

5. Ofer D, Swager TM, Wrighton MS (1995) Solid-state ordering and potential dependence of conductivity in poly (2,5-dialkoxy-p-phenyleneethynylene). Chem Mater 7:8-425

6. Zhou Q, Swager TM (1995) Fluorescent chemosensors based on energy migration in conjugated polymers: the molecular wire approach to increased sensitivity. J Am Chem Soc 117:12593-12602

7. Ramos AM, Rispens MT, Van Duren JJ, Hummelen JC, Janssen RA (2001) Photoinduced electron transfer and photovoltaic devices of a conjugated polymer with pendant fullerenes. J Am Chem Soc 123:6714-6715

8. Lère-Porte JP, Moreau JE, Torreilles C (2001) Highly conjugated poly(thiophene) $\mathrm{s}^{-}$synthesis of regioregular 3-alkylthiophene polymers and 3-alkylthiophene/thiophene copolymers. Eur J Org Chem 2001:1249-1258

9. Dhanabalan A, Van Dongen JJ, Van Duren JJ, Janssen HM, Van Hal PA, Janssen RJ (2001) Synthesis, characterization, and electrooptical properties of a new alternating $N$-dodecylpyrrole benzothiadiazole copolymer. Macromolecules 34:2495-2501

10. Wang F, Wilson MS, Rauh RD, Schottland P, Reynolds JR (1999) Electroactive and conducting star-branched poly(3hexylthiophene)s with a conjugated core. Macromolecules 32:4272-4278

11. Yamamoto T, Hayashi Y, Yamamoto A (1978) A novel type of polycondensation utilizing transition metal-catalyzed CC coupling. I. Preparation of thermostable polyphenylene type polymers. Bull Chem Soc Jpn 51:2091-2097

12. Nurulla I, Morikita H, Fukumoto H, Yamamoto T (2001) Preparation and properties of poly[(2-alkylbenzimidazole)-alt-thiophene]s with long alkyl side chains. Macromol Chem Phys 202:2335-2340

13. Krebs FC, Nyberg RB, Jorgensen M (2004) Influence of residual catalyst on the properties of conjugated polyphenylenevinylene materials: palladium nanoparticles and poor electrical performance. Chem Mater 16:1313-1318

14. Misumi Y, Masuda T (1998) Living polymerization of phenylacetylene by novel rhodium catalysts. Quantitative initiation and introduction of functional groups at the initiating chain end. Macromolecules 31:7572-7573

15. Misumi Y, Kanki K, Miyake M, Masuda T (2000) Living polymerization of phenylacetylene by rhodium-based ternary catalysts, (diene) $\mathrm{Rh}(\mathrm{I})$ complex, vinyllithium, phosphorus ligand. Effects of catalyst components. Macromol Chem Phys 201:2239-2244

16. Kishimoto Y, Eckerle P, Miyatake T, Kainosho M, Ikariya A, Noyori $R$ (1999) Well-controlled polymerization of phenylacetylenes with organorhodium(I) complexes: mechanism and structure of the polyenes. J Am Chem Soc 121:12035-12044

17. Sambiagio C, Marsden S, Blacker J, McGowan P (2014) Copper catalysed Ullmann type chemistry: from mechanistic aspects to modern development. Chem Soc Rev 43:3525-3550

18. Hassan J, Sevignon M, Gozzi C, Schulz E, Lemaire M (2002) Arylaryl bond formation one century after the discovery of the Ullmann reaction. Chem Rev 102:1359-1469

19. Liang J, Ying L, Huang F, Cao Y (2016) Recent advances in high performance solution processed WOLEDs for solid-state lighting. J Mater Chem C 4(47):10993-11006 
20. Guo F, Karl A, Xue Q (2017) The fabrication of color-tunable organic light-emitting diode displays via solution processing. Light Sci Appl 6:e17094

21. Jiang J, McGraw G, Ma R, Brown J, Yang DK (2017) Selective scattering polymer dispersed liquid crystal film for light enhancement of organic light emitting diode. Opt Express 25(4):3327

22. AISalhi MS, Alam J, Dass LA, Raja M (2011) Recent advances in conjugated polymers for light emitting devices. Int J Mol Sci 12:2036

23. Facchetti $A$ (2011) $\pi$-Conjugated polymers for organic electronics and photovoltaic cell applications. Chem Mater 23:733

24. Moliton A, Hiorns RC (2004) Review of electronic and optical properties of semiconducting $\pi$-conjugated polymers: applications in optoelectronics. Polym Int 53:1397

25. Joseph S, Ruth S (2008) Organic light-emitting devices (OLEDs) and OLED-based chemical and biological sensors: an overview. J Phys D Appl Phys 41:133001

26. Shinar R, Shinar J (2009) Organic electronics in sensors and biotechnology. McGraw-Hill Education, New York

27. Adachi C, Tsutsui T, Saito S (1990) Blue light-emitting organic electroluminescent devices. Appl Phys Lett 56:799

28. Guo T, Guan R, Zou JH, Liu J, Ying L, Yang W, Wu HB, Cao Y (2011) Red light-emitting hyperbranched fluorene-alt-carbazole copolymers with an iridium complex as the core. Polym Chem 2:2193-2203

29. Chen SH, Su AC, Su CH, Chen SA (2005) Crystalline forms and emission behavior of Poly(9,9-di-n-octyl-2,7-fluorene). Macromolecules 38:379-385

30. Sun J, Wang H, Yang T, Zhang XW, Li J, Zhang TM, Wu YL, Chen WH, Wong WY, Xu BS (2016) Design, synthesis and properties of triple-color hyperbranched polymers derived from poly(9,9-dioctylfluorene) with phosphorescent core tris(1-phenylisoquinoline) iridium(III). Dyes Pigments 125:339-347

31. Ainur A, Lena V, Denan W, Tushar S, Navale S (2019) Charge-transfer or excimeric state? Exploring the nature of the excited state in cofacially arrayed polyfluorene derivatives. J Photochem Photobiol A Chem 374:125-130

32. Huang F, Hou LT, Shen HL, Jiang JX, Wang F, Zhen HY, Cao Y (2005) Synthesis, photophysics, and electroluminescence of high-efficiency saturated red light-emitting polyfluorene-based polyelectrolytes and their neutral precursors. J Mater Chem 15:2499

33. Huang F, Hou LT, Shen HL, Yang RQ, Hou Q, Cao Y (2006) Synthesis and optical and electroluminescent properties of novel conjugated polyelectrolytes and their neutral precursors derived from fluorene and benzoselenadiazole. J Polym Sci Part A Polym Chem 44:2521

34. Inoue Y, Tokito S, Ito K, Suzuki T (2004) Organic thin-film transistors based on anthracene oligomers. J Appl Phys 95:5795-5799

35. Meng H, Sun FP, Goldfinger MB, Jaycox GD, Li ZG, Marshall WJ, Blackman GS (2005) High-performance, stable organic thin-film field-effect transistors based on bis-5'-alkylthiophen-2'-yl-2,6-anthracene semiconductors. J Am Chem Soc 127:2406-2407

36. Teng C, Yang X, Yang C, Li S, Cheng M, Hagfeldt A, Sun L (2010) Molecular design of anthracene-bridged metal-free organic dyes for efficient dye-sensitized solar cells. J Phys Chem C 114:9101-9110

37. Kim SK, Yang B, Ma Y, Lee JH, Park JW (2008) Exceedingly efficient deep-blue electroluminescence from new anthracenes obtained using rational molecular design. J Mater Chem 18:3376

38. Kondakov DY (2007) Characterization of triplet-triplet annihilation in organic light-emitting diodes based on anthracene derivatives. J Appl Phys 102:114504

39. Kim YH, Kwon SK (2006) Novel blue-light-emitting polymers based on a diphenylanthracene moiety. J Appl Polym Sci 100:2151

40. Lee T, Song KH, Jung I, Kang Y, Lee SH, Kang SO, Ko J (2006) Silylene-spaced diphenylanthracene derivatives as blue-emitting materials. J Organomet Chem 691:1887
41. Vaubel G, Baessler H (1968) Determination of the band-gap in anthracene. Phys Lett 27:328-329

42. Ding JQ, Lu JH, Cheng YX, Xie ZY, Wang LX, Jing XB, Wang FS (2008) Solution-processible red iridium dendrimers based on oligocarbazole host dendrons: synthesis, properties, and their applications in organic light-emitting diodes. Adv Funct Mater 18:2754-2762

43. Chalke RM, Patil VR (2017) Novel methoxy spirobifluorene and alkyl substituted diphenylacene based organic blue light emitting polymers for application in organic electronics. Polymer 123:355-365

44. Barve KA, Raut SS, Mishra AV, Patil VR (2011) Synthesis and studies of blue light emitting polymers containing triphenylamine-substituted fluorene and diphenylanthracene moiety. J Appl Polym Sci 122:3483-3492

45. Chalke RM, Patil VR (2017) New approaches towards the synthesis and characterization of alkoxy substituted spirobifluorenes and spirosilabifluorenes for organic optoelectronics. J Macromol Sci A 54:556-564

46. Raut SS, Barve KA, Bayes GS, Patil VR (2010) Synthesis of watersoluble polyesters containing carboxy-functional groups in the polymers chain and study of their metal complexes. J Inorg Organomet Polym 20:343-355

47. Yang J, Cheng H, Frost RL (2011) Synthesis and characterisation of cobalt hydroxy carbonate $\mathrm{CO}_{2} \mathrm{CO}_{3}(\mathrm{OH})_{2}$ nanomaterials. Spectrochim Acta Part A 78:420-428

48. Mishra AV, Hasija DC, Patil VR (2018) Novel blue-emitter-containing o-terphenyl-substituted fluorene and diphenylanthracene units. ChemistrySelect 3:13665-13669

49. Ioannis K, Vladimir YR, Jan CG, Ronald F, Alexander EL, Elisabeth $\mathrm{H}$ (2011) Arylamino-functionalized fluorene- and carbazole-based copolymers: color-tuning their CdTe nanocrystal composites from red to white. J Poly Sci Part A Poly Chem 49:392-402

50. Chia-Hung C, So-Lin H, Dinakaran K, Mao-Yuan C, Kung-Hwa W (2005) Synthesis and characterization of luminescent polyfluorenes incorporating side-chain-tethered polyhedral oligomeric silsesquioxane units. Macromolecules 38:745-751

51. Do-Hoon H, Moo-Jin P, Ji-Hoon L, Nam-Sung C, Hong-Ku S, Changhee $L$ (2004) Synthesis and light-emitting properties of polyfluorene copolymers containing a hydrazone derivative as a comonomer. Synth Met 146:145-150

52. Klarner G, Davey MH, Chen WD, Scott JC, Miller RD (1998) Colorfast blue-light-emitting random copolymers derived from di- $n$-hexylfluorene and anthracene. Adv Mater 10:993

53. Sun J, Cheng JG, Zhu WQ, Ren SJ, Zhong HL, Zeng DL, Xu EJ, Liu YC, Fang Q (2008) An X-shaped $\pi$-conjugated polymer comprising of fluorene units and anthracene units with high efficiency. Synthesis and optical and electrochemical properties. J Polym Sci A Polym Chem 46:5616

54. Wang X, Tong J, Guo P, Li Y, Li H, Xia Y, Wang F (2017) Low-bandgap conjugated polymers based on alkylthiothienyl-substituted benzodithiophene for efficient bulk heterojunction polymer solar cells. Polymer 122:96-104

55. Peng F, Xu J, Zhang Y, He R, Yang W, Cao Y (2017) Deep-blue light-emitting polyfluorenes containing spiro[fluorene-9,9' thioxanthene-S, S-dioxide] isomers. J Polym Sci A Polym Chem 55(14):2332-2341

56. Ding JF, Day M, Robertson G, Roovers J (2002) Synthesis and characterization of alternating copolymers of fluorene and oxadiazole. Macromolecules 35:3474

Publisher's Note Springer Nature remains neutral with regard to jurisdictional claims in published maps and institutional affiliations. 